\title{
A Comparison of the Diurnal Variation in Lake Surface Temperature for the Five Major Lakes of the Savannah River Basin
}

\author{
Jonathan Hodges ${ }^{1}$, J. R. Saylor ${ }^{1}$, and Nigel Kaye ${ }^{1}$
}

AUTHORS: ${ }^{1}$ Department of Mechanical Engineering, Clemson University, Clemson, SC 29634.

\begin{abstract}
Satellite measurements of lake surface temperature can benefit several environmental applications such as estimation of lake evaporation, predictions of lake overturning, and meteorological forecasts. Using a onedimensional lake simulation that incorporates satellite measurements of lake surface temperature, the average diurnal variation in lake surface temperature was obtained. The satellite measurements were obtained from the MODIS instrument aboard the Aqua and Terra satellites. Herein the functional form for the diurnal variation in surface temperature is presented for each of the five major lakes in the Savannah River Basin, which are located in South Carolina and Georgia: Lakes Jocassee, Keowee, Hartwell, Russell, and Thurmond. Differences in the diurnal variation in surface temperature between each of these lakes are identified and potential explanations for these differences are presented.
\end{abstract}

\section{INTRODUCTION}

Numerous environmentally relevant processes occur at the air/water interface of inland bodies of water such as lakes and reservoirs. For example, the stratification and mixing cycle of lakes can have a significant impact on the exchange of dissolved gases such as oxygen, carbon dioxide, carbon monoxide, and methane (Solano et al., 2000; Adrian et al., 2009; Tranvik et al., 2009; Raymond et al., 2013; Borges et al., 2015; Borges et al., 2018), and on the evaporation and condensation of water from the surface (Helfer et al., 2011; Phillips et al., 2016; Zhang et al., 2017; Bou-Fakhreddine et al., 2018). Thermal stratification and the onset of lake overturn is a balance between the stabilizing effect of solar radiation heating the water surface, nocturnal back radiation, convective cooling of the surface, and the destabilizing effect of the shear velocity of wind at the surface. Understanding the diurnal variation in water surface temperature, $T$, could improve predictions of local lake evaporation, climate modeling, and global water cycle prediction.

It is difficult to measure $T_{s}$ over the surface of a large body of water with typical in-situ techniques (Llewellyn-Jones et al., 1993). Low-cost sensors such as thermistors or thermocouples must be mounted on a floating buoy with a power supply and data acquisition capability. Recent advancements in remote sensing from satellites allow for accurate measurements of $T_{s}$ with reasonable spatial resolution (NASA, 2014; Sütterlin et al., 2015; Liu et al., 2015). The two moderate resolution imaging spectroradiometer (MODIS) satellites, Aqua and Terra, each globally measure $T_{s}$ twice per day at a spatial resolution of 1,000 m (NASA, 2014). Although a temporal resolution of four satellite measurements of $T_{s}$ per day may be sufficient for some applications-such as monthly, seasonal, or yearly trends-it may be insufficient for use in global climate modeling since the satellites are unlikely to measure the daily maximum and minimum $T_{s}$.

The thermal, hydrodynamic, and water quality of Lake Jocassee and Lake Keowee in the Savannah River Basin in South Carolina have been studied by the Army Corps in support of the relicensing of the nuclear and hydro-electric power generation systems (USACE, 2014). The thermal studies primarily focused on the height of the seasonal thermocline, the average epilimnion temperature, and the average bulk temperature. However, these studies did not model the daily behavior of the surface temperature.

Researchers have recently shown that diurnal variations in $T_{s}$ could be simulated using a one-dimensional thermal model of a lake in combination with four daily satellite measurements of $T_{s}$ (Hodges et al., 2016). The authors showed that the simulated $T_{s}$ could be used to develop a function describing the diurnal variation in $T_{s}$ for a specific lake. The main objective of this study was to apply/extend the same simulation framework to predict the diurnal variation in $T_{s}$ in the five major lakes in the Savannah River Basin (SRB) located in South Carolina and Georgia, and to develop a function describing the diurnal variation in $T_{s}$ for each lake. 


\section{Diurnal Variation in Lake Surface Temperature for Five Major Lakes of Savannah River Basin}

Each of the examined lakes were geographically close to each other, and thereby experience the same climatology; however, the physical characteristics such as area, coast length (or perimeter), depth, elevation, and shape can vary significantly. The goal of this work was to examine the impact of several of these lake characteristics on the diurnal variation of $T_{s}$.

\section{METHODS}

Lake surface temperature measurements, $T$, for each lake were obtained from the MODIS sensor onboard the Aqua and Terra satellites. The MODIS sensor provides global images at a $1-\mathrm{km}$ resolution across several spectral bands. Aqua and Terra are in a sun-synchronous, near-polar circular orbit, which provides global measurements twice a day per satellite. Although the exact time each day changes slightly, Aqua measurements are generally at 01:30 a.m./ p.m. local time while Terra measurements are generally at 10:30 a.m./p.m. local time. Researchers have developed a land surface temperature product (LST) based on the long wave infrared MODIS bands $31(11 \mu \mathrm{m})$ and $32(12$ $\mu m$ ) (Wan, 1999). The LST product was developed for land; however, it is also able to provide measurements of water surface temperature (Phillips et al., 2016). In a previous study, each lake was examined using high-resolution images from Landsat 7-ETM to develop a mask of pixels that were land-free. The average $T_{s}$ of the land-free pixels for each lake at each measurement time was used as an input to the model for the lake. The previous study identified a total of 6 , 1, 12, 3, and 19 land-free pixels for Lakes Jocassee, Keowee, Hartwell, Russell, and Thurmond, respectively (Phillips et al., 2016).

While four daily measurements of $T_{s}$ can provide insight into the seasonal processes for each lake (Phillips et al., 2016), this frequency is insufficient to determine the diurnal variation of $T_{s}$. However, by utilizing these measurements and simulating the change in temperature between them, a diurnal variation can be obtained. The hydrodynamic model used in this work is based on a classic approach solving for the heat transfer between the seasonal mixed layer, or epilimnion, and the bulk layer of the lake. In the model, $T_{s}$ is considered to be equal to the epilimnion temperature. Physically, $T_{s}$ will vary from the epilimnion temperature as the surface is heated and cooled more quickly than the seasonal layer. Although this will not capture the development of the seasonal mixed layer, Hodges et al. (2016) showed that the approach was able to predict $T_{s}$ between satellite measurements on Lake Hartwell. The simulation software developed in the prior study was used to predict $T_{s}$ between satellite measurements for each of the five lakes in this study. The increased temporal resolution of $T_{s}$ predictions from the simulation software were averaged over all days in the period investigated (2002-2014) to obtain an average functional form for the diurnal variation in each lake. An overview of the simulation methodology of Hodges et al. (2016) is provided in the following paragraphs.

The simulations employ conservation of energy applied to the lake surface and to the mixed layer, as well as a turbulent kinetic energy balance applied to the mixed layer. By integrating these equations, $T_{s}$ is obtained between the satellite measurements of $T$, at a time step $\Delta t$ that was set to 1 minute herein. Conservation of energy was applied to the surface of the lake following the method presented by Alcântara et al. (2010):

$$
\Phi_{N}=\Phi_{S}(1-A)-\left(\Phi_{r i}+\Phi_{s f}+E_{e}\right)
$$

where $\Phi_{N}$ is the net heat flux at the surface in $\mathrm{W} / \mathrm{m}^{2}, \Phi_{s}$ is the flux of incident short wave radiation in $\mathrm{W} / \mathrm{m}^{2}, \Phi_{r i}$ is the flux of long wave radiation in $\mathrm{W} / \mathrm{m}^{2}, \Phi_{s f}$ is the sensible heat flux in $\mathrm{W} / \mathrm{m}^{2}, E_{e}$ is the energy flux due to evaporation in $\mathrm{W} / \mathrm{m}^{2}$, and $A$ is the albedo of water. Details regarding the calculation of each surface energy flux are provided by Hodges et al. (2016). Conservation of energy was also applied to the mixed layer depth, using the following equation:

$$
\rho_{0} c_{p, w} H_{m} \frac{d T_{s}}{d t}=\Phi_{N}-\Phi_{E}-\Phi_{B}
$$

where $\rho_{0}$ is the reference water density in $\mathrm{kg} / \mathrm{m}^{3}, c_{p, w}$ is the specific heat capacity of water in $J / \mathrm{kg} \mathrm{K}, T_{s}$ is the surface temperature in $\mathrm{K}, \Phi_{E}$ is the energy flux due to entrainment in $\mathrm{W} / \mathrm{m}^{2}, \Phi_{B}$ is the energy flux due to heat transfer to the hypolimnion in $\mathrm{W} / \mathrm{m}^{2}$, and $H_{m}$ is the mixed layer depth in $\mathrm{m}$. Details regarding the calculation of $\Phi_{E}$ and $\Phi_{B}$ are provided by Hodges et al. (2016). Finally, the system of equations is closed via a turbulent kinetic energy balance within the mixed layer, following the method presented by Fischer et al. (1979):

$$
\frac{d H_{m}}{d t}=\frac{C_{k}^{f} q_{*}^{3}}{C_{T} q_{*}^{2}+\alpha\left(T_{S}-T_{b}\right) g H_{m}}
$$

where $C_{k}^{f}$ is the internal losses coefficient, $\alpha$ is the volumetric thermal expansion coefficient of water, $g$ is the acceleration due to gravity, $C_{T}$ is the kinetic energy coefficient, and $q_{*}$ is the velocity scale describing the balance of shear and buoyant forces (Fischer et al., 1979). The control volume used for this analysis is shown in Figure 1.

Simulations were conducted for the period from 2002 to 2014, with a time step of 1 minute to predict $T_{\mathrm{s}}$ between satellite measurements. The simulation procedure begins at the first satellite measurement within the period of record and marches sequentially through each satellite measurement. The initial mixed layer depth was fixed at $1 \mathrm{~m}$ and was tracked through the period of record. Equations (1) through (3) were solved between each pair of satellite measurements to predict 


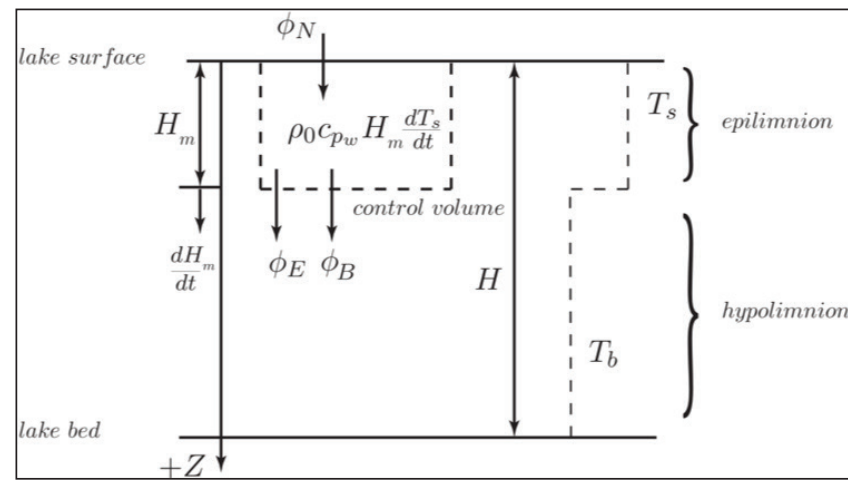

Figure 1. Control volume of the mixed layer where $H_{m}$ is the mixed layer depth, $H$ is the lake depth, $\rho_{0}$ is the reference water density, $C_{p, w}$ is the specific heat capacity of water, $T_{s}$ is the mixed layer temperature, $T_{b}$ is the bulk lake temperature, $\Phi_{N}$ is the net surface flux, and $\Phi_{E}$ is the energy flux due to entrainment.

$T_{s}$ and $H_{m}$. The solution procedure presented by Hodges et al. (2016) uses a fixed, effective wind speed between satellite observations. The effective wind speed is iteratively solved within the range of 0 and $20 \mathrm{~m} / \mathrm{s}$ to minimize errors at the next measured $T_{s}$. There were occasions when no variation in wind speed resulted in the correct $T_{s}$ due to fundamental processes not included in the model (such as precipitation). When this occurred, $C_{k}^{f}$ (summer) or $L$ (winter) were varied in addition to wind speed. Although this procedure will not fully resolve the hydrodynamic processes of lake mixing, this methodology was found to be sufficient to predict $T_{s}$ between two satellite observations (Hodges et al., 2016).

Measurements of air temperature $T_{a}$, relative humidity $\varphi$, and bulk water temperature $T_{b}$ were entered into the model. Values for $T_{a}$ and $\varphi$ were obtained from three different weather stations. The choice of weather station was determined by proximity of the station to the center of the lake. The Oconee County Regional Airport (KCEU) was used for Lakes Keowee and Jocassee, the Anderson Regional Airport (KAND) was used for Lakes Hartwell and Russell, and the Augusta Regional Airport (KAGS) was used for Lake Thurmond (Nadolski, 1998). A map of the upper Savannah River Basin is provided in Figure 2.

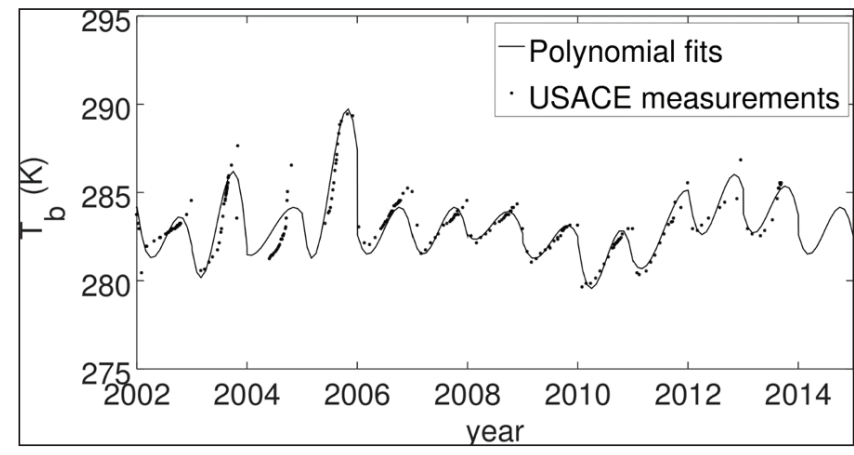

Figure 3. Lake Hartwell bulk temperature, $T_{b}$, versus year along with yearly poly fit.

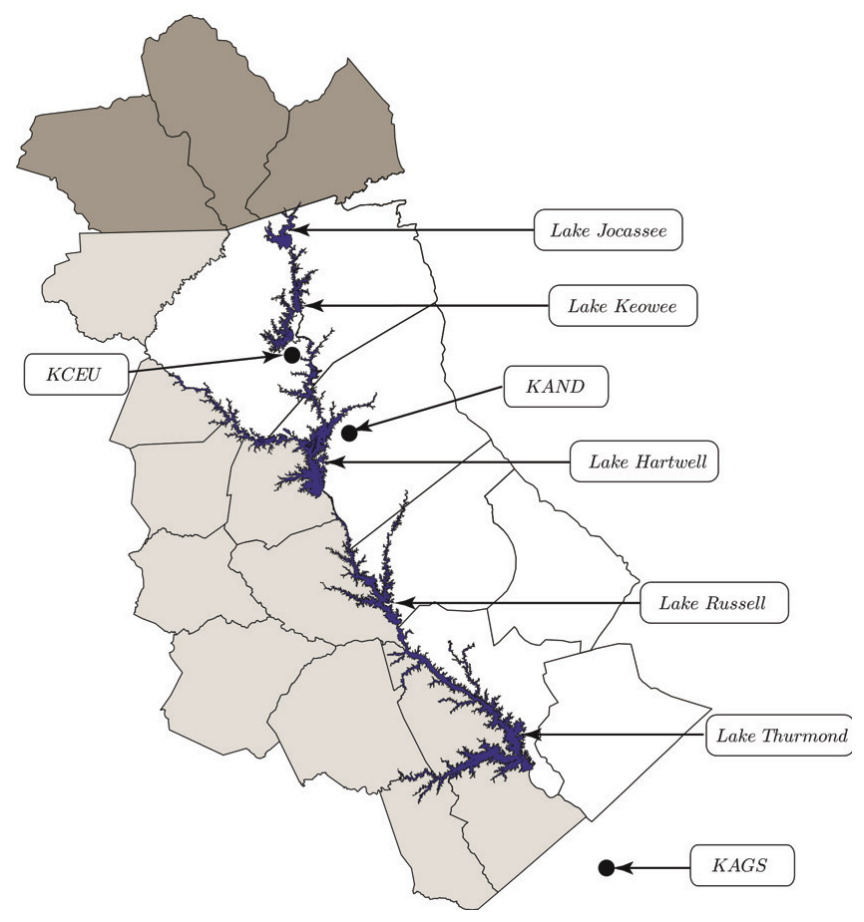

Figure 2. Map of the lakes and weather stations in the Savannah River Basin on the border between South Carolina and Georgia. Data courtesy of USACE.

Measurements of the bulk temperature of the lake, $T_{b}$, were available for Lake Hartwell from the United States Army Corps of Engineers (USACE) 6-12 times a year. To facilitate the simulations, a continuous function for $T_{b}$ was needed. Each year of $T_{b}$ data was fit by a third-order polynomial in series and the data concatenated. The initial point of each year was fixed as the final point of the polynomial curve for the previous year to ensure continuity between years. For five years $(2004,2006,2007,2013$, and 2014), there were not enough measurements available to create a good fit. For these years, the average yearly trend, obtained from the other years, was used, with a vertical offset based on the final temperature from the previous year. The measured data and polynomial fits for $T_{b}$ in Lake Hartwell are shown in Figure 3. Herein the $T_{b}$ function defined for Lake Hartwell was used for the other four lakes since historical measurements of $T_{b}$ were unavailable. Due to the way the mixed layer is treated in this approach, the model is not highly sensitive to the bulk layer temperature. Although the true $T_{b}$ for each lake is different, it was decided that using the same $T_{b}$ for each lake in this study was sufficient since the focus was to predict $T_{s}$ and it was not sensitive to $T_{b}$.

The root mean square deviation of the simulations from the satellite measurements was computed to quantify how well the simulation results match the satellite measurements of $T_{s}$ : 


$$
T_{r m s}=\left[\frac{1}{N} \sum_{n=1}^{N}\left(T_{s}^{n}-T_{s a t}^{n}\right)^{2}\right]^{1 / 2}
$$

where $n$ is the satellite measurement number, $T_{s a t}^{n}$ is the $n^{\text {th }}$ satellite surface temperature measurement, $T_{s}^{n}$ is the simulation surface temperature at the time of the $n^{\text {th }}$ atellite measurement, and $N$ is the total number of satellite measurements.

Following the method presented by Hodges et al. (2016), the time traces of $T_{s}$ were made dimensionless in both temperature and time using the following equations:

$$
\begin{gathered}
T^{*}=\frac{T-T_{\min }}{T_{\max }-T_{\min }} \\
t^{*}=\left\{\begin{array}{cc}
\frac{24+t-t_{\text {set }}}{24-t_{\text {set }}+t_{\text {rise }}}+1 & 0 \leq t<t_{\text {rise }} \\
\frac{t-t_{\text {rise }}}{t_{\text {set }}-t_{\text {rise }}} & t_{\text {rise }} \leq t \leq t_{\text {set }} \\
\frac{t-t_{\text {set }}}{24-t_{\text {set }}+t_{\text {rise }}}+1 & t_{\text {set }} \leq t \leq 24
\end{array}\right.
\end{gathered}
$$

where * indicates the dimensionless variable and the subscripts min and max denote the minimum and maximum temperatures of that day; $t$ is local time in hours, and the subscripts set and rise correspond to sunset and sunrise local time, in hours. Thus $T^{*}$ is bounded between 0 and 1 ; $t^{*}=0$ at sunrise is unity at sunset and increases to a max of 2 at sunrise on the next day. Using this scaling ensures that the growth of the diurnal thermocline begins at the same $t^{*}$ every day, which is useful for averaging across multiple days and seasons.

\section{RESULTS}

Surface temperature (K) was calculated between MODIS measurements of $T_{s}$ for the five major lakes in the Savannah River Basin. Surface temperatures were simulated from July 2002 (the first time where all four daily $T_{s}$ measurements from MODIS were available) to July 2014 for Lakes Keowee, Hartwell, and Russell. Lakes Jocassee and Keowee were simulated from 2006 to 2014 due to limited availability of KCEU measurements $\left(T_{a}\right.$ and $\left.\varphi\right)$ for earlier years. The simulations of $T_{s}$ for Lakes Jocassee, Keowee, Hartwell, Russell, and Thurmond are presented in Figure 4, revealing the annual and inter-annual variation in $T_{s}$.

The root mean square error of the simulation predicted $T_{s}$ and the satellite observed $T_{s}$ for Lakes Jocassee, Keowee, Hartwell, Russell, and Thurmond, $T_{r m s}$ were $1.5 \mathrm{~K}, 2.7 \mathrm{~K}$,

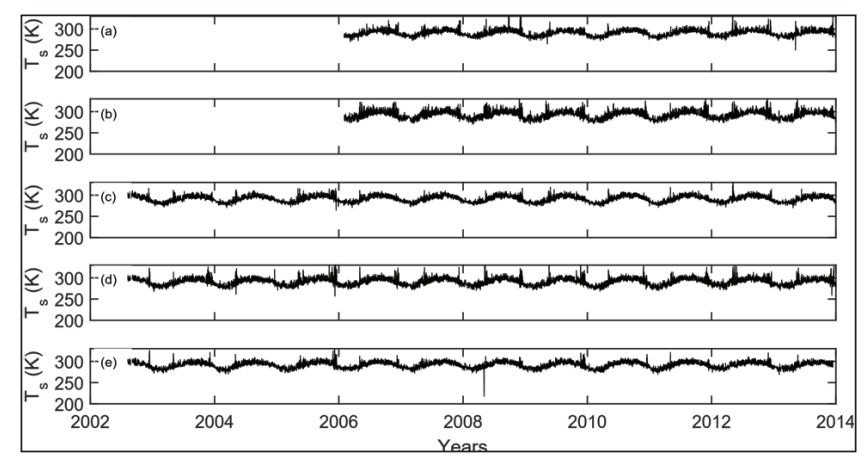

Figure 4. Lake surface temperature, $T_{s}$ in $\mathrm{K}$ versus time, $t$ in years from simulation results for Lakes (a) Jocassee, (b) Keowee, (c) Hartwell, (d) Russell, and (e) Thurmond.

$1.4 \mathrm{~K}, 2.0 \mathrm{~K}$, and $1.5 \mathrm{~K}$, respectively. There are some instances where the simulation results for $T_{s}$ deviate significantly from any of the measured values. However, these instances are rare. Indeed, for all of the lakes, $T_{s}$ deviates from the entire $\mathrm{max} / \mathrm{min}$ for the satellite data set less than $0.1 \%$ of the time. These deviations occur when the simulation predicts $H_{m}$ decreasing close to 0 (which results in large changes in $T_{s}$ for small changes in surface fluxes). These points were omitted in the averaging process and therefore had no impact on the processed results presented here.

By averaging the $T^{*}$ versus $t^{*}$ data for each day over the entire period of record for each lake, the averaged diurnal variation was obtained. This was fit to a function of the form: where $k$ is the harmonic, $f_{k}^{*}$ is the dimensionless frequency

$$
T^{*}\left(t^{*}\right)=\sum_{k=1}^{4}\left[B_{k} \sin \left(2 \pi f_{k}^{*} t^{*}-\psi_{k}\right)\right]-D
$$

of the harmonic obtained through the Fourier transform of the average diurnal cycle in $t^{\star}, B_{k}$ is the amplitude of each Fourier component, $\psi_{k}$ is the phase shift for each Fourier component, and $D$ is a DC offset. Equation (7) has nine unknown constants $\left(B_{k}, \mathrm{k}=1-4, \psi_{k}, \mathrm{k}=1-4\right.$, and $\left.D\right)$, yet there are only four measurements in a given day. The iterative solution was also used to obtain the optimal values of $\left(B_{k}, \psi_{k}, D\right)$ for the $\left(T^{*}, t^{\star}\right)$ data for each of the five lakes. The constants developed for each lake are presented in Table 1.

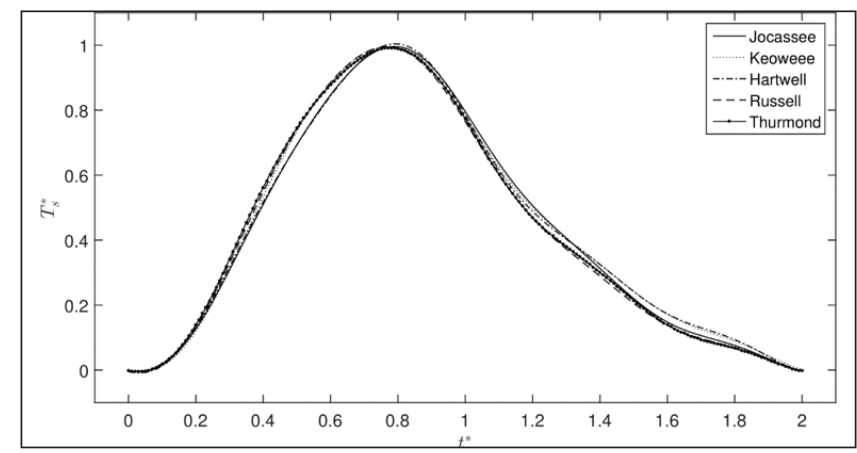

Figure 5. Plots of $T_{S}^{*}$ versus $t^{*}$ obtained from Equation (7). 
Hodges, Saylor, Kaye

Table 1. Constant values for Equation (7) for lakes in the Savannah River Basin.

\begin{tabular}{llllllllll}
\hline \multicolumn{1}{c}{ Lake } & \multicolumn{1}{c}{ c } & \multicolumn{1}{c}{$D$} & & \\
\hline Jocassee & 0.4640 & 0.1078 & 0.0033 & 0.0194 & 1.04 & 2.86 & 3.79 & 2.90 & -0.4315 \\
Keowee & 0.4595 & 0.1210 & 0.0104 & 0.0170 & 1.03 & 2.73 & 3.68 & 3.15 & -0.4395 \\
Hartwell & 0.4547 & 0.1182 & 0.0041 & 0.0241 & 1.04 & 2.81 & 6.85 & 2.86 & -0.4354 \\
Russell & 0.4662 & 0.1277 & 0.0072 & 0.0181 & 0.98 & 2.74 & 3.60 & 3.07 & -0.4285 \\
Thurmond & 0.4667 & 0.1139 & 0.0051 & 0.0233 & 0.98 & 2.71 & 3.09 & 3.19 & -0.4315 \\
\hline
\end{tabular}

The resulting versions of Equation (7) for each of the five lakes are presented in Figure 5.

\section{DISCUSSION}

Lakes Jocassee, Keowee, Hartwell, Russell, and Thurmond are geographically very close to each other and therefore experience, essentially, the same weather conditions, as shown in Figure 6 where the monthly averaged

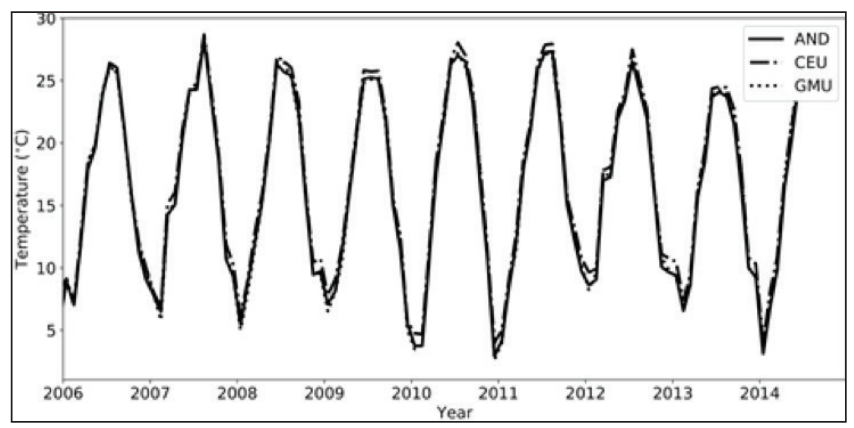

(a) Air temperature

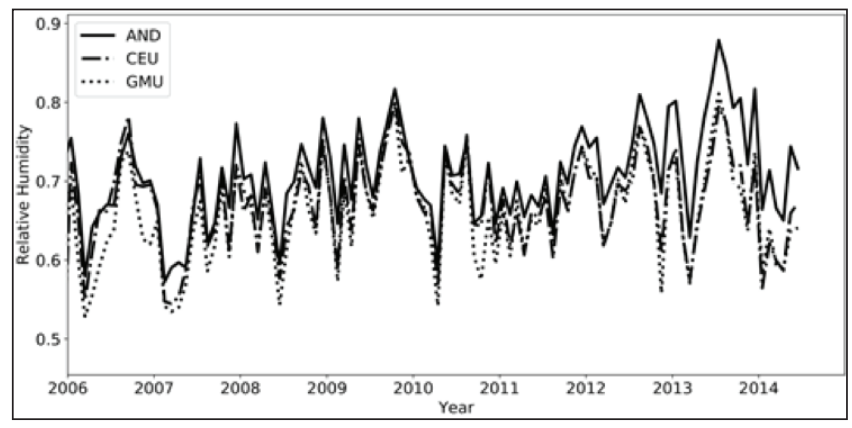

(b) Relative humidity

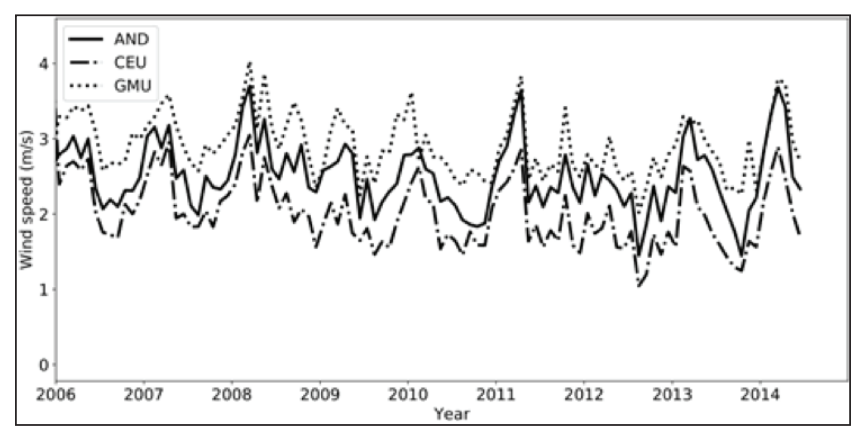

(c) Wind speed

Figure 6. Comparison of monthly average data from AND, CEU, and GMU weather stations for air temperature, relative humidity, and wind speed. air temperature, relative humidity, and wind speed data from each weather station are compared. However, several aspects of these lakes differ. This is shown in Table 2, which reveals significant differences in the depth, $H$, surface area, $A$, and shoreline length, $C$, of these lakes. In spite of these differences, as Figure 5 shows, there is almost no difference in the averaged diurnal variation in $T_{s}$ when presented in dimensionless form according to Equations (5) and (6). This suggests a certain robustness in the diurnal variation of lake surface temperature when considered in dimensionless form, although whether this robustness holds up for lakes experiencing different meteorological conditions would require further research.

Of course, by making the $T_{s}$ versus $t$ data dimensionless, significant variations are purposely masked and such variations may provide useful information. To further develop an understanding of how these lakes are similar and different, the results presented in Figure 5 were reprocessed in two additional ways, each using the same $t^{*}$ as used in Figure 5, but scaling $T_{s}$ differently. First, the daily time traces of $T_{s}$ versus $t^{\star}$ were averaged over the entire period of record for each lake. The resulting diurnal cycle is the average day for the entire data set, in Kelvins. The results are presented in Figure 7. This method has the advantage of showing vertical offsets in yearly average temperatures between the lakes.

In the second method, the daily mean is subtracted from each daily $T_{s}$ versus $t^{*}$ time trace, and then all of the days in the period of record are averaged together for each lake. This yields a time trace of the deviation from the daily mean $T_{s}$ for the simulation. The results of this approach are presented in

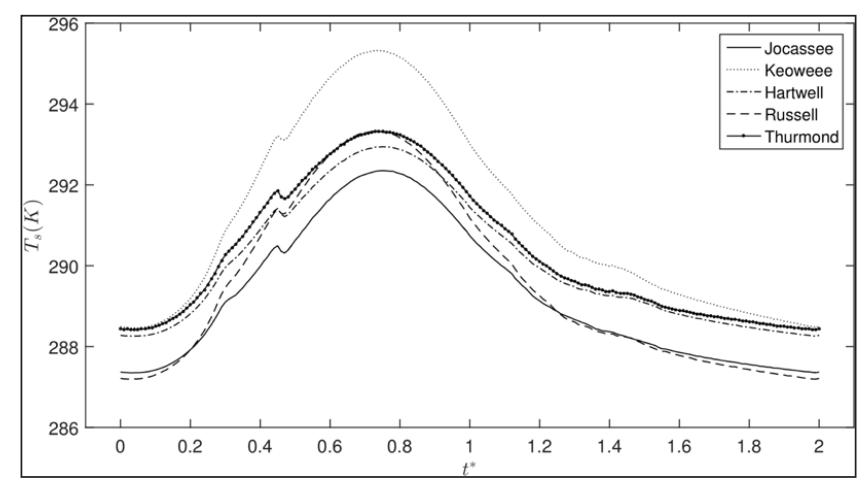

Figure 7. $T_{s}$ versus $t^{*}$ time trace obtained by averaging all daily time traces for the period of record. 


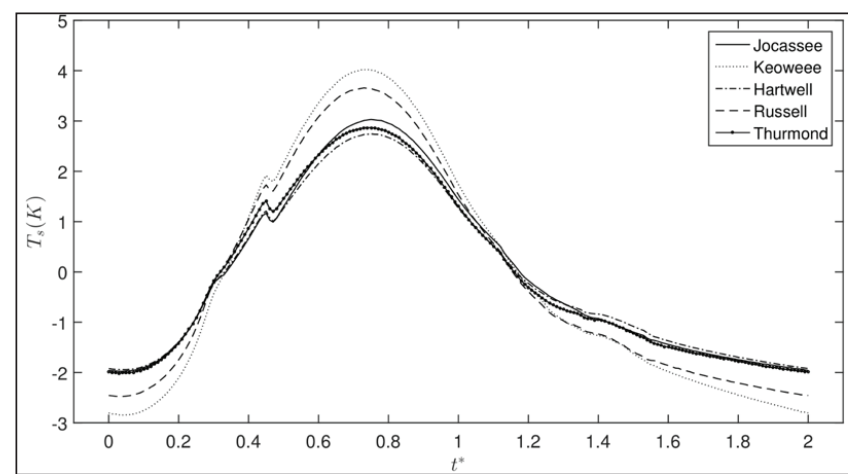

Figure 8. $T_{s}$ versus $t^{*}$ time trace where the daily mean is subtracted from each day and then all days are averaged over the period of record.

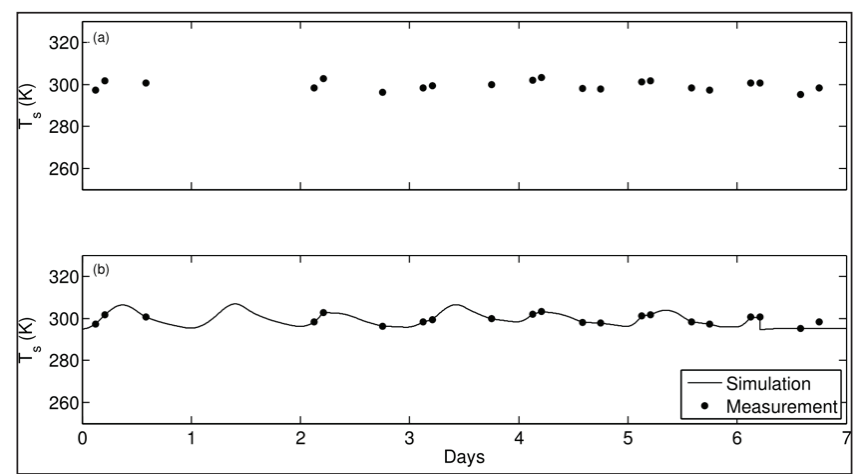

Figure 9. Surface temperature, $T_{s}$, in $\mathrm{K}$ versus day for from simulation results for a typical week where both $u_{10}$ and $c_{k}^{f}$ are large. (a) Satellite measurements only. (b) Satellite measurements and simulation results.

Figure 8. This method has the advantage of showing which lakes experience the greatest range of temperature change on an average day.

It is noted that in Figures 7 and 8 , the actual $T_{s}$ simulations are presented, not the Fourier fit which was shown in Figure 5. This is why Figures 7 and 8 are somewhat noisier. The abrupt change in temperature observed in Figures 7 and 8 between $t^{\star}=0.4$ and $t^{\star}=0.5$ is an artifact of the simulation algorithm. The algorithm iterates over wind speed between satellite measurements of $T_{\text {sat }}$. There are times (primarily in the middle of the afternoon) where two satellite measurements are very different. When disagreement with is observed, the simulation will iterate over a second parameter causing $H_{m}$ to change rapidly, which results in $T_{s}$ changing rapidly as well. An example of this result is shown in Figure 9. The second-

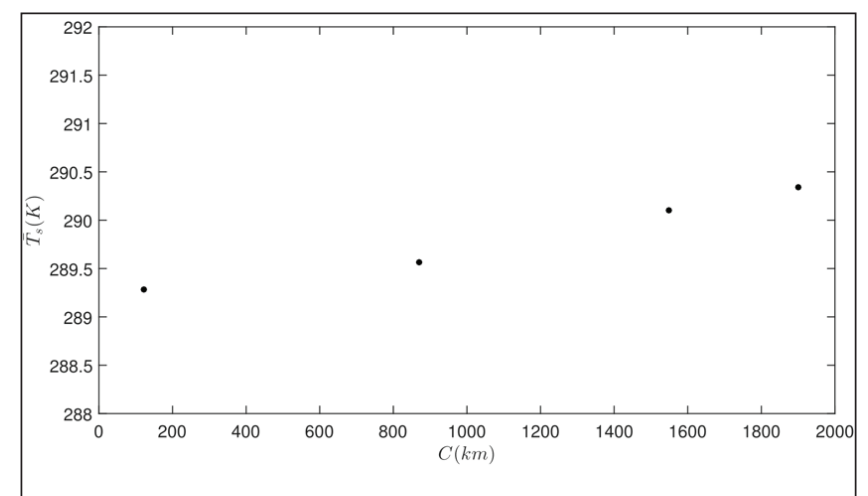

Figure 10. Average $T_{s}$ from each lake diurnal cycle versus shoreline length for the four lakes in the Savannah River Basin.

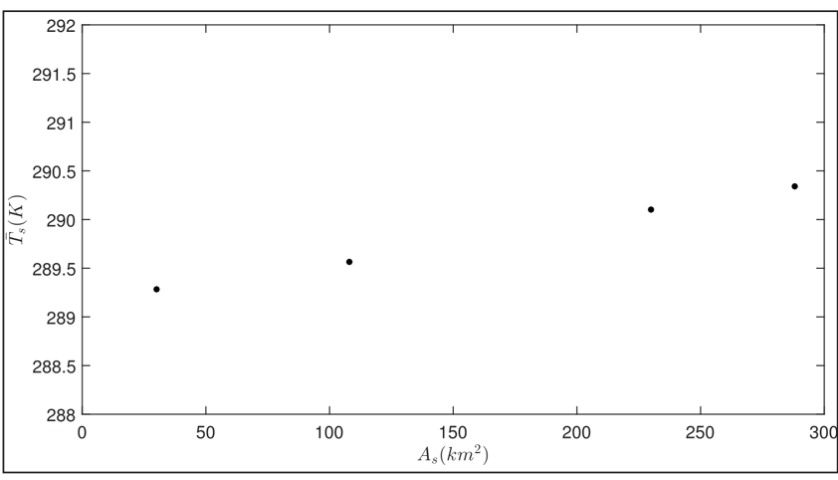

Figure 11. Average $T_{s}$ from each lake diurnal cycle versus surface area for the four lakes in the Savannah River Basin.

order discontinuity in $T_{s}$ predicted by the simulation in day 6 of Figure 9 likely does not predict the real variation in $T_{s}$. This difference could come from any number of factors that are not considered in this work. Examples include movement of a front into the region, a sudden change from clear skies to very overcast conditions and precipitation. Using precipitation as an example, a summer storm coming in after the first daytime $T_{\text {sat }}$ measurement would cause the second daytime $T_{\text {sat }}$ measurement to drop significantly. This adds uncertainty to the simulation, which, even after averaging over many days, still appears in the diurnal average.

We now seek to determine if the lake-to-lake differences shown in Figures 7 and 8 are related to any of the physical lake characteristics presented in Table 2. Observing the trends of $T_{s}$ versus $t^{*}$ shown in Figure 7, the ordering of lakes from

Table 2. Physical characteristics of lakes in the Savannah River Basin where $H_{\text {avg }}$ is the average lake depth, $H_{\max }$ is the max lake depth, $C$ is the shoreline length, and $A_{s}$ is the lake surface area.

\begin{tabular}{lccccccc}
\hline \multicolumn{1}{c}{ Lake } & Lat & Lon & Elev & $H_{\text {avg }}$ & $H_{\max }$ & $C$ & $A_{s}$ \\
\hline Jocassee & $34.96^{\circ} \mathrm{N}$ & $82.92^{\circ} \mathrm{W}$ & $340 \mathrm{~m}$ & $48 \mathrm{~m}$ & $110 \mathrm{~m}$ & $121 \mathrm{~km}$ & $30 \mathrm{~km}^{2}$ \\
Keowee & $34.80^{\circ} \mathrm{N}$ & $82.89^{\circ} \mathrm{W}$ & $240 \mathrm{~m}$ & $16 \mathrm{~m}$ & $90 \mathrm{~m}$ & $480 \mathrm{~km}$ & $100 \mathrm{~km}^{2}$ \\
Hartwell & $34.47^{\circ} \mathrm{N}$ & $82.85^{\circ} \mathrm{W}$ & $201 \mathrm{~m}$ & $14 \mathrm{~m}$ & $56 \mathrm{~m}$ & $1,548 \mathrm{~km}$ & $230 \mathrm{~km}^{2}$ \\
Russell & $34.09^{\circ} \mathrm{N}$ & $82.63^{\circ} \mathrm{W}$ & $145 \mathrm{~m}$ & $12 \mathrm{~m}$ & $45 \mathrm{~m}$ & $870 \mathrm{~km}$ & $108 \mathrm{~km}^{2}$ \\
Thurmond & $33.66^{\circ} \mathrm{N}$ & $82.20^{\circ} \mathrm{W}$ & $100 \mathrm{~m}$ & $11 \mathrm{~m}$ & $42 \mathrm{~m}$ & $1,900 \mathrm{~km}$ & $288 \mathrm{~km}^{2}$ \\
\hline
\end{tabular}


the highest average $T_{s}$ to the lowest are: Keowee, Thurmond, Hartwell, Russell, and Jocassee. None of the parameters listed in Table 2 follow this same trend. However, Lake Keowee is a heat sink for the Duke Energy Oconee Nuclear Station (ONS), and this excess energy may cause Lake Keowee's $T_{s}$ results in Figure 7 to be an outlier. The likelihood of this is supported by the experimental work of Oliver and Hudson (1987) where $T_{s}$ was observed to increase by $4 \mathrm{~K}$ when ONS became operational. Neglecting Lake Keowee, computing the average over the diurnal cycle $\bar{T}_{s}$ for the data in Figure 7, and plotting this versus $A_{s}$ and $C$ for the remaining four lakes reveals a monotonically increasing trend in both cases, as shown in Figures 10 and 11, respectively.

Both $C$ and $A_{s}$ generally increase as the size of the lake increases. However, it is not immediately apparent why a larger lake would have a higher $\bar{T}_{s}$ than a smaller lake under similar meteorological conditions. One possible explanation for the increase in $\bar{T}_{S}$ presented in Figures 10 and 11 can be explained by the existence and extent of dendrites in the lakeshore outline. Many lakes contain inlets, outlets, bays, and coves, which can account for a substantial amount of $A_{s}$ and $C$. In the SRB, these embayments can have significantly more sediment due to inflows, which may reduce the optical clarity of the water. This would result in solar insolation being absorbed into a thinner surface mixed layer, which would lead to elevated surface temperatures. In addition, many of these dendrites generally have a smaller depth than that of the rest of the lake. In some instances, these dendrites are shallow enough that solar radiation may penetrate to the bottom of the lake, thereby creating a buoyantly unstable system that causes the water to fully mix in this area. Both of these effects can result in larger $T_{s}$ in dendrites than for the rest of the lake. Wind across the surface and circulation within the lake can spread these higher $T_{s}$ regions toward the center of the lake. Thus, it would make sense for lakes with a higher proportion of dendrites to have a higher $\bar{T}_{s}$. To quantify the dendrites in the SRB, the ratio

$$
D_{r}=\frac{C}{P}
$$

was used, where $D_{r}$ is the dendritic ratio (also called the shoreline development number), $C$ is the shoreline length of the lake, and $P$ is the perimeter of a circle with a surface area equal to that of the lake. Thus, $D_{r}$ is the ratio of the actual shoreline length to the minimum possible shoreline length, which correlates to how prevalent dendrites are. As an example, the outline of Lake Jocassee $\left(D_{r}=6.2\right)$ and Lake Hartwell $\left(D_{r}=28.8\right)$ are shown side by side in Figure 12 . Values for $D_{r}$ for each lake in the SRB are presented in Table 3. A plot of versus $D_{r}$ is presented in Figure 13, which shows that $\bar{T}_{s}$ increases monotonically with $D_{r}$, which supports the theory that the prevalence of dendrites affects $\bar{T}_{s}$.

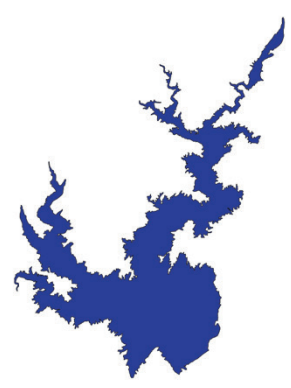

Lake Jocassee

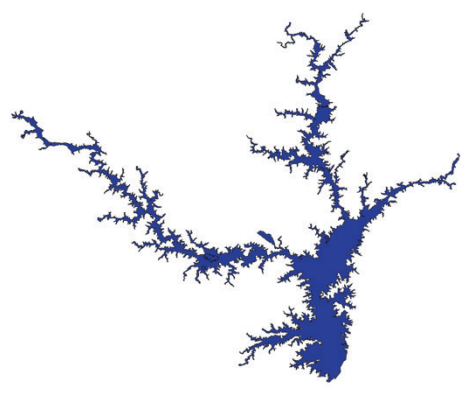

Lake Hartwell
Figure 12. Comparison of Lake Jocassee $\left(D_{r}=6.2\right)$ and Lake Hartwell $\left(D_{r}=28.8\right)$. Note that the two lakes have been scaled to appear the same size to better present the dendrites.

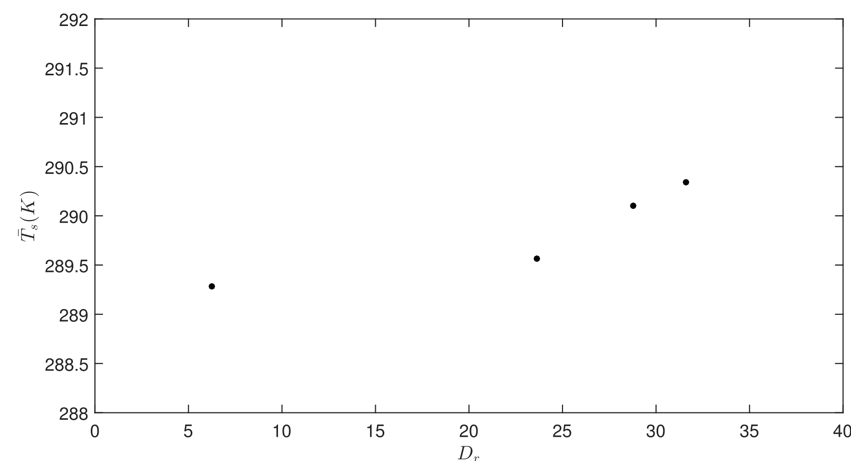

Figure 13. Average $T_{s}$ from each lake diurnal cycle versus dendritic ratio for four of the lakes in the Savannah River Basin.

To better show the relationships between $C, A_{s}$, and $D_{r}$, Equation 8 can be rewritten as the following:

$$
D_{r}=\frac{C}{2\left(\frac{4 A_{s}}{\pi}\right)^{1 / 2}}
$$

According to Equation 9, as $A_{s}$ increases, $D_{r}$ should decrease, and as $C$ increases, $D_{r}$ should increase. Figure 14 shows that the lakes in this work follow the expected trend of $D_{r}$ and $C$ being directly correlated. However, Figure 15 shows that also monotonically increases with $D_{r}$ within the SRB. This increase in the prevalence of dendrites as lake size increases in the SRB is due to $C$ increasing proportionally more than in these lakes. This is likely due to an increase in tributary basins as lake size increases in the SRB. Thus, the trends observed in Figures 10 and 11 may not be true of other basins that may have different inlet and outlet conditions. Although $\bar{T}_{s}$ scales similarly with $A_{s}, C$, and $D_{r}$ for the lakes examined in this work, using Dr provides a physical explanation for why $\bar{T}_{S}$ would behave in this way. However, additional data from lakes with varying Dr having different combinations of large and small $A_{s}$ and $\mathrm{C}$ would be needed to test this hypothesis.

Plots of the deviation from the mean of $T_{s}$ versus shown in Figure 8 indicates that Lakes Keowee and Russell 
Table 3. Dendritic ratio, $D_{r}$, for the lakes in the SRB.

\begin{tabular}{llllll} 
Lake & Jocassee & Keowee & Hartwell & Russell & Thurmond \\
\hline$D_{r}$ & 6.2 & 13.5 & 28.8 & 23.6 & 31.6 \\
\hline
\end{tabular}

experience the largest range of temperature change in the average diurnal cycle, whereas the other three lakes (Hartwell, Jocassee, and Thurmond) experience essentially the same trend. This means that on an average day, $T_{s}$ on Lakes Keowee and Russell will change more than on Lakes Hartwell, Jocassee, and Thurmond. It is intriguing that Lakes Hartwell, Jocassee, and Thurmond experience a similar trend, as Lake Jocassee is much deeper than the other two. This suggests that variations in the parameters listed in Table 2 do not affect the range of temperature change on a daily basis. However, significant differences in latitude and longitude were not considered in this work, which seem to be the parameters most likely to cause deviation in this averaging method by increasing or decreasing the length of day. None of the parameters cataloged in Table 2 explain the deviation in Lakes Keowee and Russell from the other lakes. However, if Lake Keowee is discounted for the same reasons discussed above, then the only outlier is Lake Russell.
It is possible that using $T_{b}$ measurements from Lake Hartwell for all five lakes, as was done herein, could lead to an overestimation of the collapse in the diurnal function. However, in the development of the model for Lake Hartwell, changing $T_{b}$ affected the solution for $H_{m}$ in the model but did not significantly affect $T_{s}$. This is because the model calculates an effective mixed layer depth that best fits the measurements from the MODIS instruments. Thus, changing $T_{b}$ would not affect the $T_{s}$ solution unless it was very different (Hodges et al., 2016).

To confirm that the trend observed in Figure 7 was not affected by the use of Lake Hartwell bulk measurements for all the lakes, the average $T_{\text {sat }}$ at each satellite overpass time was computed. These measurements were obtained directly from MODIS and were not affected by any assumptions made in the simulation. These average measurements are presented in Figure 16, along with the simulations presented in Figure 7. The order from minimum to maximum $\bar{T}_{\text {sat }}$ follows the same trend as that of the simulation results shown in Figure 17, which is a plot of $\bar{T}_{s}$ versus $\bar{T}_{\text {sat }}$ for each of the five lakes. Here, $\bar{T}_{s}$ is computed by averaging $T_{\text {sat }}$ for the diurnal cycle for each lake shown in Figure 7. $\bar{T}_{\text {sat }}$ is computed by averaging $T_{\text {sat }}$ shown in Figure 16 for each lake. This further demonstrates

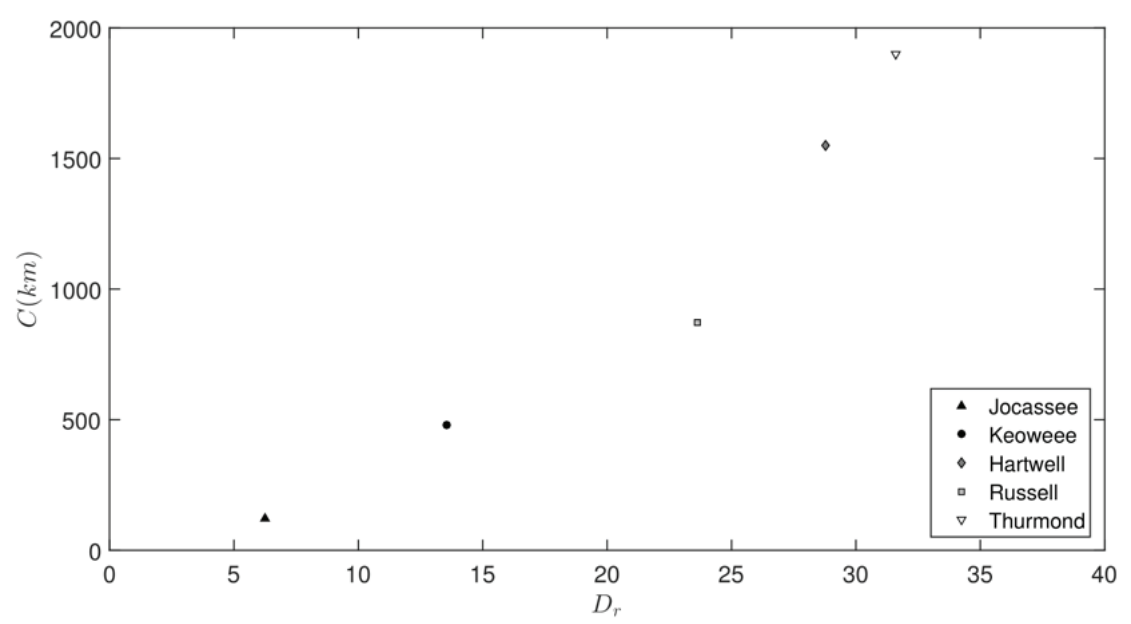

Figure 14. Lake $D_{r}$ versus $C$ for each of the lakes in the SRB.

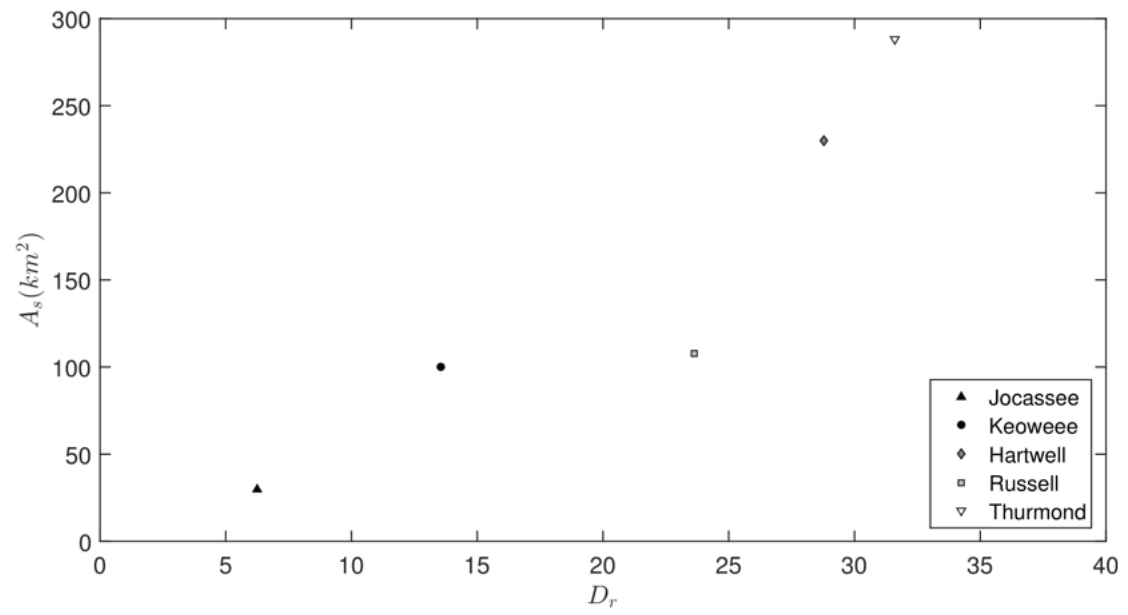

Figure 15. Lake $D_{r}$ versus $A_{s}$ for each of the lakes in the SRB. 


\section{Hodges, Saylor, Kaye}

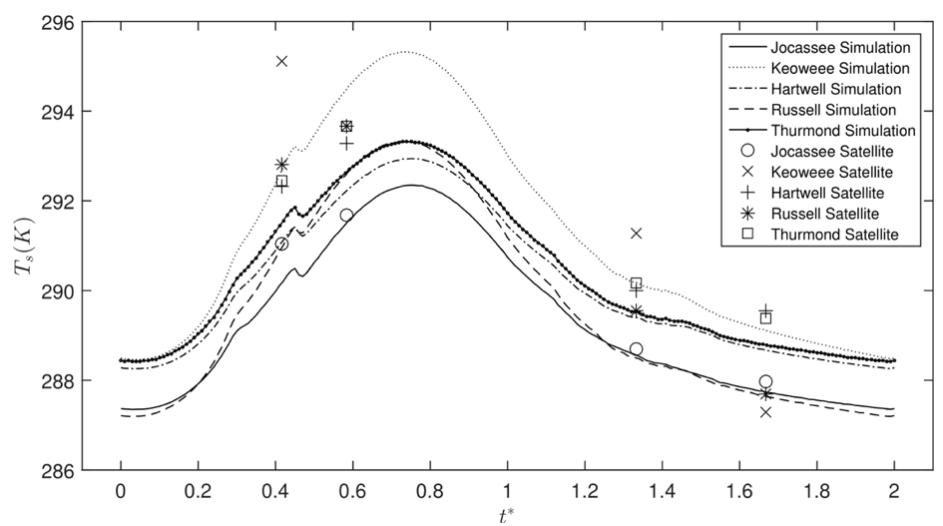

Figure 16. $T_{s}$ versus $t^{*}$ time trace obtained by averaging all daily time traces for the period of record with average $T_{\text {sat }}$

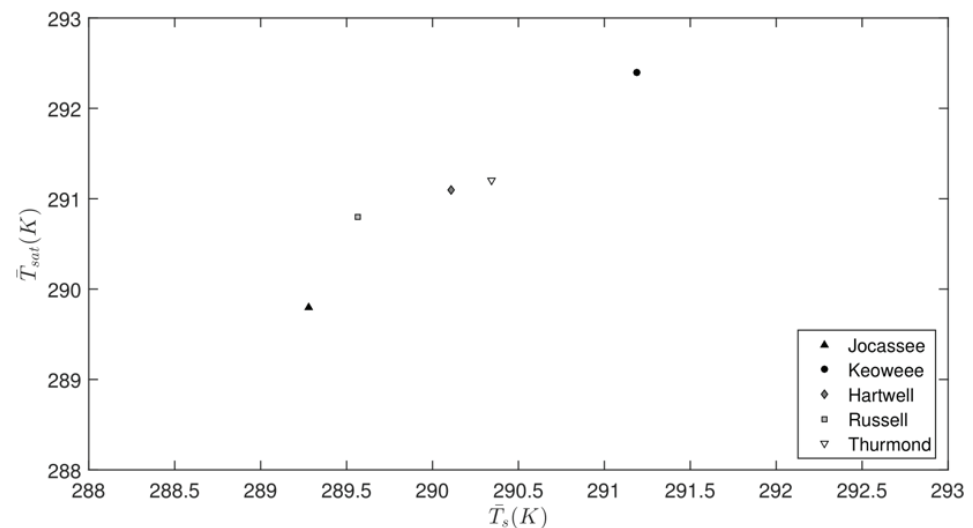

Figure 17. $\bar{T}_{s}$ and $\bar{T}_{\text {sat }}$ from each lake diurnal cycle for five of the lakes in the Savannah River Basin.

Table 4. $\bar{T}_{\text {sat }}$ for the satellite measurements on each lake.

\begin{tabular}{llllll} 
Lake & Jocassee & Keowee & Hartwell & Russell & Thurmond \\
\hline 289.8 & 292.4 & 21.1 & 290.8 & 291.2 \\
289.3 & 291.2 & 290.1 & 289.6 & 290.3 \\
\hline
\end{tabular}

that the variation in average surface temperature from lake to lake follows the same trend in the simulation results and in the MODIS measurements. The values of both $\bar{T}_{s}$ and $\bar{T}_{\text {sat }}$ are presented in Table 4 . The satellite average temperatures were generally higher than the simulation average temperatures at the same $t^{*}$. This is likely due to being limited to clear-sky days, since MODIS cannot provide through clouds. However, the simulation predicts $T$ for cloudy days even when there are dropouts. Since cloudy days would experience less solar insolation, these days would have a lower average $T_{s}$.

\section{CONCLUSION}

Simulations of hourly surface temperature, $T$, were performed on the five major lakes in the Savannah River Basin located in South Carolina and Georgia: Lakes Jocassee, Keowee, Hartwell, Russell, and Thurmond. Simulations were conducted using measurements of ambient atmospheric conditions from three airports near the lakes-the Oconee County Regional Airport, the Anderson Regional Airport, and the Augusta Regional Airport-along with bulk temperature measurements from USACE and four daily satellite-based measurements of $T_{s}$ from the MODIS sensors on NASA's two satellites, Aqua and Terra. The simulation results were collapsed based on daily temperature extrema and daily sunrise and sunset times at each of the lake study sites.

The average diurnal trends from each of the lakes were found to collapse to similar functions using the nondimensional temperature and time scales presented in this work. The consistency of the results for each of the lakes implies generality to all warm, monomictic lakes. However, the diurnal cycle of the dimensional temperature versus time does show differences between the lakes, generally scaling with shoreline length and surface area of the lake. A dendritic ratio was defined, which collapsed the effects of shoreline length and surface area on $\bar{T}_{S}$. Future investigations comparing these results to those of warm, monomictic lakes in other regions of the world would be illuminating. Additionally, future work investigating polymictic and bimictic lakes using the method presented by Hodges et al. (2016) could lead to a greater understanding of the general diurnal variation on all inland lakes and reservoirs. 


\section{Diurnal Variation in Lake Surface Temperature for Five Major Lakes of Savannah River Basin}

\section{ACKNOWLEDGMENTS}

Financial support from the USGS through the South Carolina Water Resources Center (SCWRC) is gratefully acknowledged, as is access to temperature measurements of Lake Hartwell by the US Army Corps of Engineers. Surface temperature and cloud-cover data were obtained from the MODIS Adaptive Processing System, part of the NASA Earth-Sun System Division. Ambient atmospheric measurement data were acquired from the National Oceanic and Atmospheric Administration (NOAA). The authors thank Ryne Phillips for providing processed versions of the satellite data and for his insights in support of this work.

\section{REFERENCES}

Adrian R, O’Reilly CM, Zagarese H, Baines SB, Hessen DO, Keller, W, et al. 2009. Lakes as sentinels of climate change. Limnology and Oceanography, 54(6part2):2283-2297. https://doi.org/10.4319/lo.2009.54.6_part_2.2283.

Alcântara EH, Stech JL, Lorenzzetti JA, Bonnet MP, Casamitjana X, Assireu AT, Novo EM. 2010. Remote sensing of water surface temperature and heat flux over a tropical hydroelectric reservoir. Remote Sensing of Environment, 114(11):2651-2665. https://doi. org/10.1016/j.rse.2010.06.002.

Borges AV, Darchambeau F, Teodoru CR, Marwick TR, Tamooh F, Geeraert N, et al. 2015. Globally significant greenhouse-gas emissions from african inland waters. Nature Geoscience, 8(8):637-642.

Borges AV, Speeckaert G, Champenois W, Scranton MI, Gypens N. 2018. Productivity and temperature as drivers of seasonal and spatial variations of dissolved methane in the southern bight of the north sea. Ecosystems, 21(4):583599. https://doi.org/10.1007/s10021-017-0171-7.

Bou-Fakhreddine B, Mougharbel I, Faye A, Pollet Y. 2018. Estimating daily evaporation from poorly-monitored lakes using limited meteorological data: a case study within qaraoun dam-lebanon. Journal of Environmental Management, 241:502-513.

Fischer HB, List EJ, Koh RCY, Imberger J, Brooks NH. 1979. Mixing in inland and coastal waters. London (UK): Academic Press.

Helfer F, Zhang H, Lemckert C. 2011. Modelling of lake mixing induced by air-bubble plumes and the effects on evaporation. Journal of Hydrology, 406(3-4):182-198. https://doi.org/10.1016/j.jhydrol.2011.06.020.

Hodges JL, Saylor JR, Kaye NB. 2016. A functional form for the diurnal variation of lake surface temperature on Lake Hartwell, Northwestern South Carolina. IEEE Journal of Selected Topics in Applied Earth Observations and Remote Sensing, 9(8):3564-3577. https://doi.org/10.1109/ JSTARS.2016.2555798.

Liu G, Ou W, Zhang Y, Wu T, Zhu G, Shi K, Qin B. 2015. Validating and mapping surface water temperatures in Lake Taihu: results from MODIS land surface temperature products. IEEE Journal of Selected Topics in Applied Earth Observations and Remote Sensing, 8(3):1230-1244. https://doi.org/10.1109/JSTARS.2014.2386333.

Llewellyn-Jones D, Mutlow C, Zavody A, Murray M, Allen M, Saunders R, Barton I. 1993. SST measurements from ATSR on ESA's ERS-1 satellite-early results. In: Geoscience and Remote Sensing Symposium, 1993. IGARSS '93. Better Understanding of Earth Environment, International. Piscataway (NJ): Institute of Electrical and Electronics Engineers, p. 155-156.

Nadolski VL. 1998. Automated Surface Observing System (ASOS) User's Guide [Computer software manual]. NASA. 2014. NASA Land Processes Distributed Active Archive Center (LP DAAC): MOD06L2, MYD06L2, MOD11A1, and MYD11A1. Washington (DC): NASA/ USGS.

Oliver JL, Hudson PL. 1987. Thermal and dissolved oxygen characteristics of a South Carolina cooling reservoir. Water Resources Bulletin, 23(2):258-269. https://doi. org/10.1111/j.1752-1688.1987.tb00805.x.

Phillips R, Saylor J, Kaye N, Gibert J. 2016. A multi-lake study of seasonal variation in lake surface evaporation using MODIS satellite-derived surface temperature. Limnology, 17(3):273-289. https://doi.org/10.1007/ s10201-016-0481-z.

Raymond PA, Hartmann J, Lauerwald R, Sobek S, McDonald C, Hoover M, et al. 2013. Global carbon dioxide emissions from inland waters. Nature, 503(7476):355-359. https://doi.org/10.1038/nature12760.

Solano R, Johns R, Lake L, et al. 2000. Impact of reservoir mixing on recovery in enriched-gas drives above the minimum miscibility enrichment. In: SPE/DOE Improved Oil Recovery Symposium, 3-5 April, Tulsa, Oklahoma. Richardson (TX): Society of Petroleum Engineers. https://doi.org/10.2118/59339-MS

Sütterlin M, Schaaf C, Stöckli R, Sun Q, Hüsler F, Neuhaus C, Wunderle S. 2015. Albedo and reflectance anisotropy retrieval from AVHRR operated onboard NOAA and METOP satellites: algorithm performance and accuracy assessment for Europe. Remote Sensing of Environment, 168:163-176. https://doi.org/10.1016/j.rse.2015.06.023.

Tranvik LJ, Downing JA, Cotner JB, Loiselle SA, Striegl RG, Ballatore TJ, et al. 2009. Lakes and reservoirs as regulators of carbon cycling and climate. Limnology and Oceanography, 54(6part2), 2298-2314. https://doi. org/10.4319/lo.2009.54.6_part_2.2298.

USACE. (2014). Final environmental assessment: new operating agreement between U.S. Army Corps of Engineers, southeastern power administration, and duke energy. Savannah (GA): US Army Corps of Engineers.

Wan Z. (1999). MODIS land-surface temperature algorithm theoretical basis document (LST ATBD). Santa Barbara (CA): Institute for Computational Earth System Science.

Zhang H, Gorelick SM, Zimba PV, Zhang X. 2017. A remote sensing method for estimating regional reservoir area and evaporative loss. Journal of Hydrology, 555:213-227. https://doi.org/10.1016/j.jhydrol.2017.10.007. 